\title{
Cadernos do IL o Cadernos do IL o Cadernos do IL o Cadernos do IL o Cadernos do IL
OS EFEITOS DA FALA DA CRIANÇA: A ESCUTA DO SINTOMA NA CLÍNICA DE LINGUAGEM
}

\author{
Scheila Bender ${ }^{*}$ \\ Luiza Milano Surreaux**
}

\begin{abstract}
RESUMO: O presente artigo tem como objetivo refletir sobre os efeitos da fala sintomática sobre a escuta do sintoma na clínica de linguagem. Para discorrermos sobre a noção de sujeito e sintoma na clínica de linguagem, repensando a posição do terapeuta frente à fala sintomática, realizamos uma interlocução com a linguistica da enunciação, mais especificamente a teoria de Émile Benveniste e a psicanálise freudo-lacaniana. A partir da análise de cenas enunciativas de atendimentos fonoaudiológicos propomos ao terapeuta uma reflexão sobre as singularidades da fala sintomática dos pacientes que chegam à clínica.
\end{abstract}

PALAVRAS-CHAVE: Clínica de linguagem - Sujeito - Sintoma de linguagem

ABSTRACT: The present paper aims reflect about the effects of symptomatic speech above the symptom listening on language of clinical. For discourse about the subject and symptom notion on language of clinical, rethinking the position of therapist front the symptomatic speech, we performed a interlocution with the enunciation of linguistic, more specifically the theory of Émile Benveniste and the Freudian and Lacanian psychoanalysis. From the analysis of speech therapy of enunciative scenes we propose to the therapist a reflection about the singularities of symptomatic speech of patient that came in to the clinic.

KEY WORDS: clinical language - subject- symptom language

\section{INTRODUÇÃO}

Este trabalho surge a partir de uma série de interrogantes acerca do sintoma na clínica de linguagem, dos efeitos desse sintoma no paciente e no terapeuta e na posição do terapeuta frente à fala sintomática. Interrogantes estes que partiram de uma formação e experiência clínica ${ }^{1}$ que permitiram a escuta do sintoma de linguagem na clínica de linguagem.

Para a refletirmos sobre os efeitos da fala da criança e a escuta do sintoma na

\footnotetext{
* Scheila Bender é Fonoaudióloga, Especialista em Atendimento Clínico com Ênfase em Fonoaudiologia pela UFRGS. E-mail: scheilabender@hotmail.com

Luiza Milano Surreaux é Fonoaudióloga, Doutora em Estudos da Linguagem e Professora Adjunta do Instituto de Letras da UFRGS. E-mail: surreaux@uol.com.br

1 Neste estudo, referimo-nos especialmente aos atendimentos clínicos realizados na Clínica de Atendimento Psicológico da UFRGS, que é uma clinica de atendimento à comunidade voltada para a formação de alunos da graduação de Psicologia e Fonoaudiologia da UFRGS e para os alunos da Especialização em Atendimento Clínico.
} 
clínica de linguagem, recorreremos a autores que abordaram em seus estudos a noção de normal e patológico na clínica de linguagem e sobre a noção de sintoma. Propomos uma clínica que se distancie da clínica médica tomada pelo orgânico e aproximamo-nos de uma clínica que olha para o sujeito e suas particularidades.

Assim, após discorrermos sobre o sintoma na clínica de linguagem, buscaremos na linguística da enunciação, mais especificamente na teoria de Émile Benveniste, e na psicanálise freudo-lacaniana, reflexões sobre as noções de sujeito e sua relação com a linguagem e sobre o conceito psicanalítico de transferência, para assim, podermos discutir a noção de sintoma na clínica de linguagem e repensarmos a posição do terapeuta frente à fala sintomática.

Teremos ainda, com o presente trabalho, o objetivo de repensar a posição do terapeuta de linguagem frente à fala sintomática, a partir das contribuições teóricas de Cláudia de Lemos, sobre a aquisição da linguagem e, conforme já destacado, dos estudos de Émile Benveniste, no campo da linguística da enunciação.

\section{O SINTOMA NA CLÍNICA DE LINGUAGEM}

Como lembra Surreaux (2006), a clínica de linguagem é bastante influenciada pela clínica médica "fazendo com que a tomada de um paciente em tratamento se dê pela via do patológico (em oposição ao "normal")", assim, "investiga-se" a história do paciente, buscando circunscrever a origem do "não funcionamento (ou do mal-funcionamento) da linguagem". (op.cit.: 88)

Está aí o ponto de partida das intervenções na clínica de linguagem: pode-se classificar em normal ou patológico aquilo que "não vai bem" na linguagem de um paciente? O que é isso que "falha" na fala de um paciente?

Lier De-Vitto (2007) lembra que mesmo que o sintoma na fala seja reconhecido como acontecimento, não é reconhecido como singular e enigmático. Um exemplo disso são os aparatos descritivos a que são submetidas as falas sintomáticas, que não consideram as especificidades e que as classificam como "erro", desconsiderando os efeitos que o sintoma produz no sujeito e no outro. Para Lier De-Vitto, sintoma é o que leva o sujeito à clínica, pois envolve sofrimento. Ele deixa marcas por efeito de um enlaçamento singular do sujeito à sua fala e acaba por isolar o sujeito dos outros falantes da língua.

Em Sobre o sintoma de linguagem na clínica de linguagem, Surreaux (2009) busca na psicanálise outra interpretação sobre aquilo que falha na fala dos sujeitos, pois a noção de sintoma na clínica de linguagem é marcada pelos interrogantes que essa falha evoca. A autora acredita que os pressupostos psicanalíticos proporcionam uma escuta para o dizer do sujeito. Assim, tendo em jogo o sujeito em sofrimento no âmbito da linguagem, "é necessário realizar um deslocamento para além da abordagem sígnica (médica) do sintoma, para que possa haver uma escuta do sujeito que anuncia o sofrimento em sua forma peculiar de falar" (op.cit.:23).

Como lembra Surreaux (2009), o tratamento em uma abordagem patologizante 
se dá pela via reparadora, que dê conta da supressão "daquele mal-estar produzido pela marca de mal ou pouco falante do paciente em questão" (op.cit.:32). É por isso que a autora busca em seus estudos investigar e propor uma "perspectiva de sintoma de linguagem como combinação singular por parte do sujeito que enuncia" (op.cit.:32).

Se a linguagem tem particularidades para cada sujeito, e assim, tem irregularidades, na fala sintomática o que está irregular toma maior destaque. Como lembra Surreaux (2006), "não basta lidar com a noção de patologia apriorística, cuja aplicabilidade é limitada. Sem dúvida, ela aponta um conhecimento sobre o que é visível (ou audível) na fala do paciente, mas jamais falará sobre a forma particular de cada sujeito estar na linguagem" (op.cit.:92).

Ao contrário do terapeuta que possui o "saber-controle", o terapeuta que reflete sobre a singularidade da fala sintomática de seus pacientes emerge de um sujeito que está capturado pelo funcionamento da língua. Araujo (2007) lembra que nessa posição em que o fonoaudiólogo reflete sobre as singularidades do sujeito que procura a clínica, "o outro concebido como instância, não é o outro empírico, mas concebido como lugar. Ele não pode, portanto, ser confundido com "individualidade" (op.cit.:398). A autora segue apontando que "pensar o outro como instância do funcionamento da língua significa reconhecê-lo como sujeito dividido entre fala e escuta, e, portanto, sob efeito de falas - da própria e do outro" (op.cit.:389). É dessa posição de escuta de falante que o sujeito pode, ou não, estranhar o singular de uma fala e interpretá-la.

Pensar no patológico, no que se pode ver e ouvir na fala do paciente limita o terapeuta. Enxergar só o que não vai bem impossibilita pensar no funcionamento da linguagem da paciente. Surreaux (2009) lembra que "o que deve ser priorizado pelo clínico de linguagem é a particularidade do funcionamento do inusitado (da combinação singular que surge na fala do paciente) e não na performance patológica já standartizada" (op.cit.:31). Então, afastando-nos do pensamento clínico que se preocupa somente com aquilo que é evidenciado, passível de "classificação patológica", abre-se apossibilidade de pensar em um terapeuta que considere o funcionamento da linguagem do paciente. O papel do terapeuta de linguagem, conforme Surreaux (op.cit.:34), será de "um interlocutor privilegiado, que escuta e reconhece aquela formação linguageira como tendo um sentido possível" . A autora acredita que a posição de escuta do terapeuta possibilita que ele escute a "produção criativa de seu paciente desde um lugar de suporte" (op.cit.).

A noção de suporte é sugerida por Surreaux em duas formas, próprias à clínica de linguagem:

(...) por um lado, o terapeuta sustenta aquela fala subversiva para reconhecer em seu paciente um falante, ou seja, imaginar um lugar de falante para aquele que vem sendo considerado um não-falante (ou mal-falante), criando um contexto que se considera o paciente como um par em posição de enunciação; e, ao mesmo tempo ele suporta, às vezes por muito tempo, a repetição de uma fala sintomática até o momento em que o sujeito dela conseguir se apropriar e produzir deslocamentos, fazendo uso criativo de seu sintoma, ou seja, se permitir falar desde outra posição enunciativa. (SURREAUX, 2009:35) 
Para isso, pode-se buscar nas reflexões da psicanálise uma forma de pensar o que é isso que falha quando o paciente fala e, assim, poder pensar em sintoma como sendo uma posição que o sujeito ocupa na língua, como condição peculiar de um momento desse sujeito. Como afirma Surreaux (2006:176), "se o sujeito é sempre efeito de seu próprio dizer, é necessário analisar quais as particularidades dos efeitos que causam uma fala sintomática no dizer daquele que a enuncia". O sintoma na clínica de linguagem deveria ser revisto e diferenciado daquele sintoma geralmente encontrado na clínica médica, pois acabamos nos atendo às "marcas" deixadas pelo que é chamado de patológico e deixamos de observar as "marcas" deixadas pelo sujeito.

\section{O SUJEITO NA CLÍNICA DE LINGUAGEM: INTERLOCUÇÃO COM A LINGUÍSTICA DA ENUNCIAÇÃO}

Buscamos uma clínica de linguagem que permita uma escuta singular que reflita sobre o funcionamento de linguagem daquele que procura auxílio. Salientamos que, no presente artigo, recorreremos à linguística da enunciação, mais especificamente à teoria de Émile Benveniste, que introduz em seus estudos linguísticos, entre tantas reflexões, a noção de sujeito e sua relação com a linguagem. Além disso, recorremos à psicanálise para buscar reflexões sobre as noções de sujeito e transferência, para podermos pensar na noção de sintoma na clínica de linguagem.

Sabemos que diferentes autores, sob diferentes perspectivas, introduziram suas reflexões aos estudos da enunciação. Pois então, por que buscamos em Émile Benveniste aportes para a clínica de linguagem? Se, ao se pensar em linguística da enunciação podemos remeter a uma mesma temática, que é a enunciação, acreditamos que os estudos de Benveniste possam contribuir muito para a clínica de linguagem que se interessa pela enunciação, pelo sujeito e pelas suas singularidades. Em seus estudos, o enfoque está na irrepetibilidade e a inclusão do sujeito no discurso. $\mathrm{O}$ ato de enunciar é único e irrepetível, pois depende de fatores que também são únicos a cada situação, esses fatores são ligados ao tempo (agora), ao espaço (aqui) e à pessoa (eu/tu).

Em seu trabalho intitulado Da subjetividade na linguagem, Benveniste (2005) questiona o caráter instrumental da linguagem. O autor acredita que, se a linguagem tem função comunicativa, é porque os homens não encontraram um meio melhor e mais eficaz para se comunicar. Assim, o papel de transmissão desempenhado pela linguagem pode estar ligado a meios não linguísticos e, principalmente, ao fato de que nos deixamos enganar ao falar da linguagem como um instrumento, por certos processos de transmissão que nas sociedades humanas são posteriores à linguagem. Para Benveniste, todos os caracteres da linguagem, assim como a natureza imaterial, seu funcionamento simbólico, sua organização articulada e o fato de ter um conteúdo, já nos mostram que a linguagem não pode ser simplificada a um instrumento, que acaba por afastar do homem a propriedade da linguagem.

Em O Aparelho Formal da Enunciação, Benveniste (2006) afirma que a "enunciação supõe a conversão individual da língua em discurso". O autor lembra que 
um mesmo sujeito jamais reproduz exatamente os mesmos sons. Assim, Benveniste refere que a enunciação é composta por: o próprio ato, as situações que ele se realiza, os instrumentos de sua realização. Após a enunciação, "a língua é efetuada em uma instância de discurso, que emana de um locutor, forma sonora que atinge um ouvinte e que suscita uma outra enunciação de retorno." (op.cit.:83-4).

É por meio da realização individual que a enunciação irá se definir, em relação à língua, como processo de apropriação. É no ato individual pelo qual utilizou a língua que o locutor é introduzido como parâmetro nas condições necessárias da enunciação. Como bem lembra o autor, "antes da enunciação, a língua não é senão possibilidade de língua" (op.cit.:83). Ao se declarar locutor e assumir a língua, ele coloca o outro diante de si; assim, toda a enunciação é uma alocução que pede um alocutário. $\mathrm{O}$ ato individual de apropriação acaba introduzindo aquele que fala em sua própria fala. Dessa forma, a presença do locutor na enunciação faz com que cada instância de discurso constitua um centro de referência interno.

Por isso, trazemos essas reflexões de Benveniste, embora introdutórias, para pensarmos na clínica de linguagem. Se a linguística da enunciação permite considerar a linguagem do sujeito pelo que ela tem de singular, podemos deslocá-la também para a clínica de linguagem, para considerarmos o sujeito que chega à clínica procurando auxílio em sua fala "sintomática". Concordamos com Flores (2007:100) ao dizer que:

“o estudo da 'patologia' de linguagem com relação ao sujeito que enuncia permite ao clínico a construção de recursos de análise que possibilitam elaborar hipóteses sobre o funcionamento da linguagem, ou seja, sobre a singularidade da 'patologia' para cada sujeito na instância enunciativa".

E o sujeito? Segundo Flores e Teixeira (2005) o sujeito não é o objeto de estudo da teoria linguística, mas sim a representação que a enunciação dá ao sujeito. Assim, a linguística da enunciação não discute o sujeito que enuncia, mas as marcas que ele deixa em seu enunciado, tendo seu olhar voltado para a enunciação. Para discutirmos o estatuto subjetivo daquele que enuncia, recorreremos a uma exterioridade teórica: a psicanálise freudo-lacaniana.

\section{O SUJEITO NA CLÍNICA DE LINGUAGEM: INTERLOCUÇÃO COM A PSICANÁLISE}

A partir das reflexões acerca da linguística da enunciação, abriremos discussão para outro tema a ele ligado: a noção de sujeito. Vimos anteriormente, que é no discurso que o locutor se enuncia como sujeito e que a subjetividade que Benveniste propõe para a linguagem tem a ver com a capacidade que o locutor tem para se propor como sujeito.

Segundo Zimerman (2001), Freud empregou primeiramente o termo sujeito na psicanálise, mas foi Lacan que o introduziu de forma mais definida na literatura psicanalítica. Conforme o autor, Lacan introduziu a concepção de sujeito "no âmbito de sua teoria do significante, ou seja, da relação do sujeito com o significante" 
(op.cit.:396).

De acordo com Zimerman (2001), Lacan diferenciou Outro e outro - grafandoas de duas maneiras diferentes, cada um com um significado específico. Assim, ele emprega a palavra outro chamando-a de pequeno outro, que se refere mais diretamente à alteridade, ou seja, "a relação do sujeito com seu meio, com seu desejo e com os objetos (mãe, pai, irmãos), através dos mecanismos de identificação imaginária com esses outros" (op.cit.:308). Já o grande Outro, foi descrito por Lacan para "designar um lugar simbólico que, tanto pode ser um significante, a lei, o nome, a linguagem, o inconsciente, ou, ainda, Deus, que determina o sujeito, tanto inter como intrasubjetivamente, em sua relação com o desejo" (op.cit.:308).

Em seu trabalho intitulado O nascimento do sujeito, Dunker (2008) descreve os quatro "modos de reação" que se articulam no processo de constituição do sujeito. Primeiramente, segundo o autor, quando o adulto fala com a criança ele a insere em seu desejo e em sua linguagem, simultaneamente. A descoberta do desejo do Outro inserese em um segundo momento de experiências, que está relacionado com os cuidados realizados pelo adulto para com a criança. Segundo Dunker, ao cuidarmos de uma criança também erotizamos seu corpo, ajudando na constituição de um corpo pulsional e não somente um corpo biológico e funcional.

Em um terceiro momento, a criança começa a assumir uma imagem de si mesma, fazendo parte do que Lacan chamou de estádio do espelho, "um dos momentos formativos do eu". Lacan (1998), em sua teoria do Estádio do Espelho, refere que precisamos entendê-lo "como uma identificação no sentido pleno que a análise atribui a este termo, ou seja, a transformação produzida no sujeito quando ele assume uma imagem - cuja predestinação para esse efeito de fase é suficientemente indicada pelo uso, na teoria do antigo termo imago" (op.cit.: 97).

Segundo Lacan (op.cit.), o estádio do espelho "é um drama cujo impulso interno precipita-se da insuficiência para a antecipação", produzindo no sujeito as fantasias que vão desde uma imagem despedaçada do corpo até uma forma de sua totalidade. É no momento em que o sujeito "conclui" o estádio do espelho que se inicia, "pela identificação com a imago do semelhante, (...), a dialética que desde então liga o eu a situações socialmente elaboradas" (op.cit.:101).

A noção de sujeito circunscrita pela psicanálise auxilia-nos a situar desde que lugar se considera aquele que chega ao clínico com um sofrimento no campo da linguagem. Assumir uma concepção de sujeito é, portanto, fundamental para contextualizar a escuta que se faz do paciente na clínica de linguagem.

Segundo Yañez (1990), o terapeuta deverá fazer uma escolha ao tomar uma criança em tratamento: ou fica no papel de quem ensina, supondo possuir um saber do que acontece com o corpo da criança, com a linguagem ou no seu processo de aprendizagem, ou dar lugar ao aparecimento dos desejos do sujeito, levando em conta suas possibilidades. Nessa perspectiva Yañez afirma, em relação à clínica de linguagem:

"O fundamental no nosso trabalho está centrado na emergência do sujeito e seu desejo, na criação de um espaço linguístico e na compreensão dos fenômenos transferenciais. Se isto não acontecer, tudo o que se fizer, será no campo da fala e não da linguagem, fala no sentido mais elementar e 
primitivo, sem consequências e sem efeitos no campo da subjetividade, que é o que, em última instância, mais importa no campo do sujeito, desde qualquer ato clínico que nos proponhamos a realizar." (YAÑEZ, 1990:66).

Na prática clínica, percebemos que seja qual for a especificidade do profissional, se seu trabalho estiver atravessado pela concepção psicanalítica de sujeito, a transferência repercute na relação entre o terapeuta e o paciente, fazendo com que se produzam questionamentos no discurso técnico. Segundo Yañez, a transferência se instala quando há um "Outro nesse lugar encarnado no terapeuta a quem o paciente confia sua capacidade de produzir, dizer, jogar e criar" (op.cit.:70). Então, "a transferência se estabelece na suposição de que um outro (encarnado no terapeuta) possui um saber que lhe pertence. Isto de supor que outro sabe, acontece em todos os âmbitos da vida; é por isso que a transferência é universal" (op.cit.:72).

Para a clínica de linguagem, se o terapeuta se sente completo em seu saber profissional, acaba exprimindo um poder que submete e aliena. O paciente e seus familiares não conseguem vir a constituir o seu próprio saber sobre a linguagem, anulando o principal objetivo, que é o de fazer surgir o sujeito e seus desejos, como o desejo de dizer.

\section{COMO SUSTENTAR UM "LUGAR DE EU" NA FALA TENDO UMA FALA SINTOMÁTICA?}

Como já mencionado anteriormente, a teoria da enunciação de Émile Benveniste pode contribuir muito para a clínica de linguagem. Sabemos que o autor não dedicou seus estudos à fala sintomática, mas, para uma clínica que se interessa pela enunciação, pelo sujeito e por suas singularidades, seus estudos que contemplam e incluem o sujeito no discurso, contribuem para pensarmos no lugar que o sujeito ocupa na linguagem. Com o objetivo de repensar a clínica de linguagem e o papel do terapeuta frente à fala sintomática, acrescentaremos aos estudos enunciativos aqui contemplados, contribuições dos estudos interacionistas de Cláudia de Lemos sobre a aquisição da linguagem. Vale ressaltar que não temos como objetivo discutir o termo "aquisição" nem nos determos nesta temática, mas sim, refletir, a partir de uma interlocução entre os estudos de Émile Benveniste e de Cláudia de Lemos, sobre a relação terapeuta/paciente/sintoma na clínica de linguagem.

\section{O LUGAR DE EU NA PERSPECTIVA DA LINGUÍSTICA DA ENUNCIAÇÃO}

Abordaremos a questão da condição de fala daquele que enuncia apartir da leitura de Émile Benveniste em A natureza dos pronomes (2005). Benveniste contesta o fato de nos referirmos ao pronomes como formadores de uma mesma classe. O caráter universal dos pronomes e de suas noções faz com que o autor considere que o problema 
dos pronomes é ao mesmo tempo um problema de linguagem e um problema de línguas. $\mathrm{O}$ autor apresentou os pronomes como sendo um problema de linguagem, pois eles não constituem uma classe específica, mas sim, classes diferentes, sob a condição de linguagem do qual são os signos.

Segundo o autor, alguns pronomes fazem parte da sintaxe da língua, outros são característicos do que chamou de "instâncias do discurso", ou seja, "atos discretos e cada vez únicos pelos quais a língua é atualizada em palavra por um locutor" (op.cit.: 277). Distinguir os pronomes pessoais dos outros pronomes por uma classificação que os separe não é suficiente. Segundo Benveniste, a definição comum dos pronomes pessoais que integram os termos $e u$, $t u$, ele, anula a ideia de "pessoa". Para o autor, a noção de pessoa é própria de eu e tu e falta em ele.

Benveniste destaca um lugar crucial de $e u$ e $t u$ na organização referencial dos signos linguísticos. Para o autor, "cada instância de emprego de um nome refere-se a uma noção constante e objetiva, apta a permanecer virtual ou atualizar-se num objeto singular, na representação que desperta" (op.cit.:278). Porém, "as instâncias de emprego de eu não constituem uma classe de referência, uma vez que não há 'objeto' definível como eu ao qual se possam remeter identicamente essas instâncias" (op.cit.:278). Assim, cada $e u$ tem sua referência própria, correspondendo cada momento a um único ser proposto como tal.

Segundo Benveniste, eu e tu refere uma "realidade de discurso", e isso é muito singular. Eu indica a "pessoa" que enuncia a presente instância de discurso que contém $e u$. A forma $e u$ só tem efetividade linguística no "ato de palavra que a profere", e neste processo estão interligadas duas instâncias: "de $e u$ como referente e de instância de discurso contendo eu como referido" (op.cit.:279), na troca eu-tu. Com a introdução da alocução em seus estudos, pode-se obter uma melhor descrição para o $t u$, "como o indivíduo alocutado na presente instância de discurso contendo a instância linguística $t u$ " (op.cit.:279). Essa descrição propõe $e u$ e $t u$ como uma categoria da linguagem e aponta sua dependência ao ato de fala em que estão contextualizados.

Também tem destaque nos estudos de Benveniste, os advérbios aqui e agora. Estes, relacionados ao $\mathrm{eu}$, demarcam a "instância espacial e temporal coextensiva e contemporânea da presente instância de discurso que contém eu" (op.cit.:279). O autor lembra que não adianta definir pela deíxis os termos originados da mesma relação ao aqui e agora (hoje, ontem, amanhã, etc.) e os demonstrativos, se não se ressaltar que a deíxis é "contemporânea da instância de discurso que contém o indicador de pessoa". Os pronomes não aludem à realidade nem a posições objetivas no tempo ou no espaço, e sim à enunciação, única, que os contém refletindo o seu próprio emprego.

A arriscada vulneralibidade da significação dos deíticos é razoavelmente resolvida na instância do discurso. De acordo com Benveniste, a linguagem resolveu o problema da comunicação intersubjetiva instituindo um conjunto de signos "vazios", sempre disponíveis, que se tornam "plenos" logo que o locutor os assumir em cada instância de seu discurso. Segundo o autor, é "identificando-se como pessoa única pronunciando eu que cada um dos locutores se propõe alternadamente como 'sujeito"' (op.cit.: 281). Os indicadores $e u$ e $t u$ não existem senão pelo modo em que são 
atualizados na instância de discurso, marcando em cada uma o processo de apropriação pelo locutor. Pode-se pensar assim, no lugar que o sujeito ocupa na linguagem e os efeitos produzidos pelo sujeito ao enunciar desde este lugar. Efeitos que deixam marcas tanto naquele que enuncia como naquele que é seu interlocutor.

Benveniste, ainda em A natureza dos pronomes, abre discussão para um outro ponto fundamental, a noção de ele. Para o autor, existem "enunciados de discursos" que não se referem à noção de "pessoa", que não se remetem nem a eles mesmos, mas sim a uma "situação objetiva", a chamada "terceira pessoa". A não-pessoa, é a única forma de enunciação capaz de não remeter a ela mesma, assim, a "terceira pessoa" diferencia-se de $e u$ e $t u$ por sua função e por sua natureza. Para o autor, a "terceira pessoa", ou a "não-pessoa", distingue-se, primeiramente, pela propriedade de ser combinada com qualquer referência de objeto; em segundo lugar, por jamais ser reflexiva da instância de discurso; em terceiro, por comportar um número bastante grande de variantes pronominais ou demonstrativas; e, por último, por não ser compatível com o paradigma dos termos referenciais como aqui, agora, entre outros.

Como já vimos, em Da subjetividade na linguagem, Benveniste lembra que "é na linguagem e pela linguagem que o homem se constitui como sujeito; porque só a linguagem fundamenta na realidade, na sua realidade que é a do ser, o conceito de "ego" (2005:286). A partir disso, o autor entra em outro aspecto, essencial à temática deste trabalho. Para Benveniste, a consciência de si mesmo só é possível se for experimentada por contraste: "eu não emprego eu a não ser dirigindo-me a alguém que será na minha alocução em $t u$ ” (op.cit.:286). Assim, essa condição de diálogo é constitutiva da pessoa, pois implica reciprocidade: para que "eu me torne tu na alocução daquele que por sua vez se designa por eu" (op.cit). A linguagem só é possível porque cada locutor, ao se apresentar como sujeito, remete-se a ele mesmo como eu em seu discurso e constitui o outro como $t u$.

Para Benveniste, a polaridade das pessoas é na linguagem condição fundamental, porém, essa polaridade não significa igualdade ou simetria: eu tem sempre uma posição transcendente ao $t u$, mas nenhum dos dois se concebe sozinho. É pela realidade dialética que engloba os dois termos, o que os define pela relação mútua, que se descobre o fundamento linguístico da subjetividade. Nesse quadro, o ele (a nãopessoa) figura como aquilo do que se fala. É nesse contexto que acreditamos que interesse a reflexão sobre o lugar enunciativo que se contitui um "lugar de eu" para os sujeitos que carrgeam a marca de "mal falante".

\section{O LUGAR DE EU NA PERSPECTIVA INTERACIONISTA DE AQUISIÇÃO DE LINGUAGEM}

Nos estudos interacionistas sobre a aquisição da linguagem, pode-se destacar a proposta de Cláudia de Lemos, linguista brasileira que se dedicou aos estudos em aquisição da linguagem, resgatando na linguística autores como Ferdinand de Saussure e Roman Jakobson e buscando a noção de Outro nos estudos do psicanalista Jacques 
Lacan.

O papel do Outro é discutido por Cláudia De Lemos (1986) já desde seu conhecido trabalho $A$ sintaxe no espelho. Para esta autora, na sequência de objetos linguísticos produzidos pela criança estão associados os dados linguísticos apresentados a ela pelo adulto. A autora considera o diálogo enquanto "inter-ação ou atividade conjugada" (op.cit.:10), pois os turnos de cada enunciador mostram relações de interdependência. São esses os "processos constitutivos do diálogo enquanto matriz de significação" (op.cit.). De Lemos, em sua primeira proposição teórica, nomeia estes processos de especularidade, complementaridade e reciprocidade.

O processo de especularidade é fundamental para que aconteça os outros dois. Antes de a criança participar efetivamente do diálogo com um adulto, a mãe recorta fragmentos do comportamento verbal do bebê, neste processo de especularidade, que vai ganhando visibilidade no espelho a partir de uma atividade em que a mãe atribui um sentido, que ela necessita para fazer sentido enquanto mãe. É pelo espelho do Outro que é possível, "através do que é percebido como semelhante dar conta do que é, na origem do movimento, diferente" (op.cit.:13).

Dessa mesma época é seu outro trabalho Sobre a aquisição de linguagem e seu dilema (pecado) original (1982) no qual a autora reflete também sobre a incorporação pela criança de segmentos da fala do adulto. De Lemos destaca que, em determinadas situações de interação na vida adulta, a recontextualização e a reorganização de determinados segmentos segue sendo evidenciada. O que particulariza esse processo (especularidade) na aquisição da linguagem é o fato de que a criança passa por um período de dependência do enunciado do adulto. Nessa dependência dialógica, a autora particulariza os três processos descritos acima que mostram a dependência entre do enunciado da criança e o enunciado do seu interlocutor adulto.

O primeiro processo é o de especularidade ou incorporação, já descrito anteriormente, no qual a criança toma parte ou todo enunciado do adulto a nível segmental. Vale ressaltar que De Lemos aproxima o processo de especularidade da ideia de espelho (em contraposição à noção de imitação), que coloca em questão o conhecimento linguístico como conhecimento iminente na fala da criança. O segundo processo é o de complementaridade, que se divide em intra e inter turnos. Na complementaridade inter-turnos, as respostas da criança irão preencher um lugar "semântico", "sintático" e "pragmático" estabelecido pelo enunciado imediatamente antecedente do adulto. No processo de complementaridade intra-turnos, o enunciado da criança resulta da incorporação de parte do enunciado do adulto imediatamente anterior com a combinação de um vocábulo complementar. O terceiro processo é o de reciprocidade, no qual a criança já se coloca de forma reversível em ambos os polos em uma situação dialógica.

Duas décadas mais tarde dos estudos acima destacados, De Lemos recoloca sua proposta sob a ótica de três fenômenos pelos quais a criança passa na aquisição (cf. Andrade, 2003): "1) a incorporação de fragmentos da fala do outro, 2) a natureza dos "erros" e, 3) a surpreendente heterogeneidade das produções da criança. No primeiro fenômeno é necessário reconhecer a importância da função do outro, sendo que a 
repetição de fragmentos da fala do adulto pela criança, dão indícios à alienação.

Assim, passa-se a considerar a aquisição da linguagem como uma mudança na relação "criança-língua-fala", onde a criança muda de posição em uma estrutura que articula entre estes três polos. É a partir da posição da criança nesta estrutura que o processo será caracterizado: "na primeira posição, pela dominância da fala do outro, na segunda posição, pela dominância do funcionamento da língua, e, na terceira posição que a criança, enquanto sujeito falante, divide-se entre aquele que fala e aquele que escuta sua própria fala" (op.cit.:75).

De Lemos destaca os acontecimentos em cada uma das posições da criança na estrutura "sujeito-língua-fala" e as interrogações que podem surgir sobre a escuta da criança. Na primeira posição, De Lemos dá destaque ao caráter fragmentário que tem os enunciados das crianças e à dependência da fala e da interpretação do outro, não sendo possível considerá-los somente como uma reprodução dos enunciados do outro, "porque há língua em funcionamento implicada no processo de subjetivação, o que impede pensar em 'coincidência entre a fala da criança e a do outro." (op.cit.:76). Há dominância do polo do outro e, assim, "as relações entre os significantes que vêm do outro dão a ver o funcionamento da língua e um processo de subjetivação por ele regido, isto é, que aponta para um sujeito emergente no intervalo entre os significantes do outro" (De Lemos In: Andrade, 2003:77).

Para refletir sobre a segunda posição, De Lemos formula outra questão: "alienado ao próprio movimento da língua o que [o sujeito] escuta do que fala?". A autora lembra que a segunda posição é caracterizada por "sequências paralelísticas e erros: as cadeias produzidas pela criança são permeáveis à intromissão de cadeias latentes na cadeia manifesta, produzindo cruzamentos que interferem na progressão do diálogo e do texto narrativo" (De Lemos, In: Andrade, 2003:80). Assim, os erros indicam certo afastamento da criança em relação à fala do outro e são concebidos como dominância de uma operação de natureza metafórica.

O que caracteriza a escuta do sujeito na terceira posição é a capacidade de retroação, havendo reformulações e correções, mostrando que a criança tem escuta para a cadeia significante, que irá dirigir a progressão. Segundo Andrade, a retroação indica uma mudança na estrutura. Segundo essa autora, De Lemos acredita ser esse o indício da "emergência de um sujeito em outro intervalo: naquele que se abre entre a instância que fala e a instância que escuta" (op.cit.:86). A criança reconhece que há disparidade entre o que ela diz e o que deve dizer, mesmo não chegando à forma correta.

Como se pode acompanhar, desde a perspectiva interacionista de Claudia de Lemos a constituição de um lugar de fala para o sujeito está na dependência do dizer do outro, representante da língua constituída. Nesse sentido, reconhecemos certa aproximação entre sua proposta e a de Émile Benveniste ${ }^{2}$.

Acreditamos que a interlocução realizada entre os estudos interacionistas sobre a aquisição da linguagem de Cláudia de Lemos e os estudos da linguística da enunciação

\footnotetext{
${ }^{2}$ Para maior detalhamento de uma proposta em Aquisição de Linguagem na perspectiva da Linguística da Enunciação, sugerimos a leitura de SILVA, C.L C. A criança na linguagem: enunciação e aquisição. Campinas, SP: Pontes Editores, 2009.
} 
de Émile Benveniste permitem repensar a clínica de linguagem. A partir destes estudos, buscamos refletir sobre a escuta do sintoma de linguagem e os efeitos produzidos naquele que procura a clínica e no terapeuta de linguagem. Partindo de pressupostos que permitem considerar o sintoma de linguagem de cada sujeito, podemos repensar a clínica desde um outro lugar, que possibilita escutar o sintoma e pensar nos efeitos da fala sintomática sobre o sujeito e seus interlocutores.

\section{ANÁLISES}

Apresentaremos a seguir, alguns trechos de sessões de atendimento fonoaudiológico ${ }^{3}$ transcritos e analisados conforme base teórica apresentada neste trabalho. O objetivo destas análises é refletir sobre uma clínica que se ocupa do sujeito e seu sintoma de linguagem e sobre o papel do terapeuta frente a essas particularidades. É importante lembrar que a transcrição da cena clínica não tem o objetivo de mostrar a totalidade dos acontecimentos. Isso seria impossível, visto a complexidade que representa uma sessão de atendimento e o fato da transcrição ser sempre única, estando na dependência do ponto de vista de análise de quem transcreve $e^{4}$.

$\mathrm{Na}$ primeira cena é possível observar que a paciente repete enunciados da terapeuta. Estas repetições, em um primeiro momento, seriam classificadas como típicas de um paciente com ecolalia. O que podemos refletir, a partir de nosso aporte teórico é que não se trata de meras repetições, mas de repetições como possibilidade de enunciação:

Cena 1: Terapeuta e paciente, uma menina de seis anos, brincam com bonecas e panelinhas. A paciente vai pegar uma panela e encontra uma boneca sem sapatos.

T:

P:

\footnotetext{
${ }^{3}$ Os dados analisados integram o Banco de Dados Enunsil (Enunciação e sintoma na linguagem) da pesquisa "Enunciação e Distúrbios de Linguagem", coordenada pelo Prof. Dr. Valdir do Nascimento Flores, junto ao Instituto de Letras da UFRGS. Este grupo de pesquisa é composto por linguistas, fonoaudiólogos e psicanalistas e é fruto de uma parceria entre o Instituto de Letras da UFRGS e a Clínica de Atendimento Psicológico da UFRGS.

${ }^{4}$ Convenções das transcrições:

Em cada início de transcrição será fornecido o contexto da cena enunciativa; $\mathrm{P}$ (paciente);

Os atos de fala serão divididos em duas colunas, sendo cada um identificado por T (terapeuta) e

Os trechos serão nomeados como cenas e são descritos em ordem cronológica, identificado como um número dentro de colchetes ([X]), mostrando a sequência do atendimento;

(.) um ponto entre parênteses indica uma pausa curta intra ou interturnos; intra ou interturnos .

(...) três pontos entre parênteses indicam que há uma pausa longa

Trechos transcritos entre duas barras (/X/) são trechos onde os interlocutores mudam de entonação, fazendo vozes de personagens;

(( )) parênteses duplos indicam comentários do transcritor sobre o contexto enunciativo restrito.
} 
[1] vamo fazê suco

[3] ó otro nenê

[5] vamu procurá o sapatu

$[7](\ldots)$

[9] tá sem o sapatu o nenê

[11] ((colocam o sapato)) coloca

[13] mais um né? ((colocando o outro sapato))

[15] pronto! Agora o nenê não tem mais frio no pé!
[2] a ninê ((encontra outra boneca nos brinquedos))

[4] óta papápu ninê ((mostra o pé da boneca sem sapato))

[6] atu

[8] ó, pepé

[10] papu

[12] óca

[14] deu!

Nesta cena pode-se observar que a paciente passa por um certo "descolamento" da fala do outro, como em [1] e [2], [3] e [4] e [13] e [14]. Pode-se pensar neste processo de repetição guiada pela voz do outro como ponto de partida para a paciente poder enunciar, tratando-se não de meras repetições, mas de um modo de estar na língua que passa pela repetição do dizer de $t u$ no discurso do $e u$, mas que possibilita um lugar ao sujeito que enuncia.

A atitude do terapeuta frente ao sintoma de linguagem poderá produzir deslocamentos na posição do sujeito na língua. É no diálogo, na relação com o outro, que se constitui o $e u$ e é assim que se produz um deslocamento de um sujeito que "não é entendido" para um sujeito que "é entendido". Possibilitar uma intervenção que coloca o paciente em uma posição de par no diálogo implica em o terapeuta se propor como interlocutor que reconhece a fala do paciente como possível, atribuindo sentido à cena clínica e ao dizer do paciente.

Pode-se pensar que em [2], [4] e [14], por exemplo, a paciente apropria-se da língua para introduzir algo novo, implicando-se na relação dialógica, supondo um interlocutor que possa dar continuidade no diálogo.

Para considerar o sujeito e seu sintoma é necessário que o terapeuta se proponha como interlocutor e não como reeducador da fala sintomática. Como lembra Benveniste, eu só emprego eu para dirigir-me a alguém que será na minha alocução um $t u$, sendo essa condição de diálogo constitutiva da pessoa, implicando reciprocidade: para que eu me torne $t u$ daquele que irá designar-se como eu. É posicionando-se como interlocutor que o terapeuta poderá dar sentindo ao que muitas vezes não é interpretado pelos demais interlocutores do paciente, podendo colocar a fala do sujeito em movimento. 
Vejamos outra cena:

Cena 2: terapeuta e paciente, um menino de seis anos, brincam com carrinhos e um posto de gasolina.

T:

[17] ele era muito caro?

[19] ah, ele era sem dinheru?

[21] eu quiria dirigí um fogueti, quiria comprá eli!

[23] eu comprei sem dinheru?

[25] tá

[27] /que barulho é esse/?? essi moço me vendeu um fogueti barulhento

[29] eli voua, vô pru ispaço
P:

[16] e daí, daí, daí, daí nin nindém tompava

[18] não, é tausa ti (.) ela putausa ti ela sem dinhelu não ia (.) ia as pessoa não tinha dinhelu

[20] é

[22] daí tu num dava pá tompá (...) daí u fodeti vuô, tu tu tompô eli

[24] sim (...) tá, daí tu (.) daí tu ela essi, tu tava dilizindu

[26] daí tu dissi: /qui baúlio/ (...) fala!

[28] i daí daí o fodeti baulhento (...)

[30] ué? Tu não tilia um fodeti pá i no espaçu?

Na cena acima, pode-se observar um exemplo do que De Lemos chamou de segunda posição. O paciente permanece em um mesmo espaço textual, o paralelismo (a relação da criança com a gramática) exerce função de relação: "as substituições ocorrem numa cadeia que, bem ou mal, sustenta um efeito de sentido e também faz com que a criança apareça como narrador" (ANDRADE, 2003:83). Em [28] e [30] o paciente se apropriou do enunciado da terapeuta para construir outro enunciado em seguida.

Segundo Andrade, as pausas, hesitações e retomadas de um significante mostram uma criança afetada pelo desarranjo que foi produzido em sua fala, por uma ruptura de restrição sintática, assim, a autora acredita haver uma escuta, por parte da criança, de um sujeito que emerge nas diferenças. Podemos observar que o paciente interrompe sua fala, hesita, redireciona, como em [18], [22] e [24]. Mas é assim que a língua está presente, é necessário um estranhamento, o silêncio para que possa aparecer o "estranho", o "irregular", para que a criança possa, pelo estranhamento do outro, escutar-se.

Retornando ao diálogo com Benveniste, podemos observar na cena acima os indicadores que segundo o autor exprimem a subjetividade da linguagem. Esses 
indicadores da deíxis têm o papel de organizar as relações espaciais entre os sujeitos e se definem somente quando relacionados à instância do discurso em que são produzidos. Isto é, estão na dependência dos pronomes $e u / t u$ e são o ponto de partida da subjetividade na linguagem. Como já citado anteriormente os pronomes eu/tu só existem pelo modo em que são atualizados no discurso, marcados pelo processo de apropriação pelo locutor, podendo-se pensar no lugar em que o sujeito ocupa na linguagem e nos efeitos produzidos no sujeito e no seu interlocutor ao enunciar desde esse lugar.

Pode-se também, observar os efeitos e a repercussão que a escuta provoca. Porém, é supondo o outro que o sujeito consegue enunciar, do mesmo modo que o terapeuta de linguagem consegue se colocar no papel de interlocutor, pois supõe o outro também como interlocutor, considerando sua singularidade e seu sintoma, mas acima de tudo considerando o sujeito e sua forma de estar na língua. Se Benveniste pressupõe o uso da língua pelo sujeito considerando a enunciação como o processo po meio de um ato individual de utilização, podemos pensar no falante "não ideal" em sua singularidade a cada ato de enunciação.

O trabalho em clínica de linguagem deve ser considerado a partir da perspectiva do sujeito, de seu sintoma e de suas singularidades, o que irá permitir que o sujeito ocupe uma posição na língua, percebendo que é possível enunciar e passível de ser entendido. E é na interlocução entre $e u$ e $t u$, na qual $e u$ pode se reconhecer como singular, diferente de $t u$, que será possível que o sujeito se direcione ao outro como seu interlocutor, em uma cena enunciativa. Ocupar-se de uma clínica do singular, que leva em consideração a imprevisibilidade do sujeito e de sua fala, permite pensar em intervenções que emanam dos efeitos que essas falas produzem na escuta do clínico. É desde esse lugar que o terapeuta de linguagem estará em condições de sustentar a posição de interlocutor para o paciente e com ele buscar constituir efeitos de sentidos.

\section{CONCLUSÃO}

A partir do percurso realizado no presente trabalho foi possível observar que pensar nas "falhas" da fala da criança como sintoma de linguagem - sendo o sintoma de linguagem uma forma peculiar de este marcar sua posição na língua - é o que permite olhar para o sujeito e suas particularidades. Como vimos, a clínica fonoaudiológica pode ganhar muito quando se propõe a buscar na interlocução com a psicanálise as noções de sujeito, transferência e sintoma, deixando de ver como patológico aquilo que não vai bem na fala do paciente e, consequentemente, passando a tomar o sintoma de linguagem como algo singular do sujeito que enuncia.

Acreditamos que a escuta do sintoma nos remete à questão da alteridade da linguagem. Se o sintoma de linguagem causa sofrimento ao sujeito e estranhamento aos seus interlocutores, o terapeuta que permite em sua clínica a escuta do sintoma consegue promover mudanças na posição que o sujeito se coloca na língua, considerando-o como interlocutor no diálogo. 
Igualmente, o diálogo com a linguística - e particularmente aqui destacamos a Linguística da Enunciação - aponta para um fértil espaço de discussão sobre as formas tão heterogêneas por meio da quais os pacientes vislumbram um lugar de fala. Percebemos que constituir-se como enunciador apartir da relação com o outro é determinante da relação que o sujeito trava com a língua.

As análises de cenas enunciativas de atendimento fonoaudiológico permitiramnos perceber, entre tantas questões, que é extremamente significativo na clínica de linguagem um espaço de escuta aberto pelo terapeuta como interlocutor, dando sustentação à posição do paciente como um falante da língua. É este movimento que poderá produzir deslocamentos na posição do sujeito na língua. Não podemos esquecer que na posição de escuta do terapeuta estão repercutindo a todo o momento os efeitos de estranhamento, angústia, silêncio, interpretações. Não se aborda por completo a fala do paciente, não se conhece o todo do sintoma que este apresenta e é este "não saber" que permite ao terapeuta escutar o sintoma de linguagem desde uma posição não positivada.

Assim, uma clínica de linguagem marcada pela escuta do singular deve considerar a imprevisibilidade da fala do sujeito que está em tratamento. A partir dos efeitos que a fala sintomática produz na escuta do terapeuta é que se pode pensar nas intervenções na cena clínica e assim sustentar uma posição de interlocutor para o paciente.

\section{REFERÊNCIAS}

ANDRADE, Lourdes. Ouvir e escutar na constituição da clínica de linguagem. 2003. Tese (Doutorado em Linguística Aplicada e Estudos da Linguagem) - PUCSP, São Paulo, RS.

ARAÚJO, Sônia Maria. Clínica de Linguagem: sobre a posição do fonoaudiólogo na relação com a fala sintomática de crianças. In: LIER-DE-VITO, Maria Francisca; ARANTES, Lúcia Maria. Aquisição, patologias e clínicas de linguagem. São Paulo: Editora PUC-SP, 2007.

BENVENISTE, Émile. A natureza dos pronomes. In: Problemas de linguística geral I. São Paulo: Pontes Editores, 2005. . Da subjetividade na linguagem. In: . Problemas de linguística geral I. São Paulo: Pontes Editores, 2005. O aparelho formal da enunciação. In:

II. Campinas, São Paulo: Pontes Editores, 2006. - Problemas de linguística geral DE LEMOS, Cláudia. Sobre a aquisição de linguagem e seu dilema (pecado) original. Boletim da Abralin. Recife: Ed. Universitária da Universidade Estadual de Pernambuco, 1982.

- A sintaxe no espelho. Cadernos de Estudos Linguísticos - Unicamp, Campinas, n. 10, 1986.

DUNKER, Cristiano Ingo Lenz. O Nascimento do Sujeito. Revista Mente e Cérebro. São Paulo, v.2, n.2, 2008. 
FLORES, Valdir do Nascimento; SURREAUX, Luiza Milano e KUHN, Tanara

Zingano. Enunciação e sintoma de linguagem: um estudo sobre as relações metafóricas e metonímicas. Calidoscópio - Unisinos, São Leopoldo, v. 03, nº 02, maio/agosto de 2005.

FLORES, Valdir; TEIXEIRA, Marlene. Introdução à linguística da enunciação. São Paulo: Contexto, 2005.

FLORES, Valdir Nascimento. Benveniste e o sintoma de linguagem: A enunciação do homem na língua. Letras de Hoje - PUCRS, Porto Alegre, v. 33, n.2, 2007.

LACAN, Jaques. O estádio do espelho como formador da função do eu. In:

Escritos. Rio de Janeiro: Jorge Zahar, 1998.

LIER-DE-VITO, Maria Francisca. Patologias da linguagem: sobre as "vicissitudes de falas sintomáticas". In: LIER-DE-VITO, Maria Francisca; ARANTES, Lúcia Maria. Aquisição, patologias e clínicas de linguagem. São Paulo: Editora PUC-SP, 2007. SURREAUX, Luiza Milano. Linguagem, sintoma e clínica em clínica de linguagem. 2006. 202f. Tese (Doutorado em Letras) - Instituto de Letras, UFRGS, Porto Alegre, RS.

. Sobre o sintoma de linguagem na clínica de linguagem. In: GRAÑA, Carla Guteres (org.) Quando a fala falta: Fonoaudiologia, lingüistica e psicanálise. Porto Alegre: Casa do Psicólogo, 2009.

YAÑEZ, Zulema Garcia. Desde o verbo de Nicolás: a transferência na terapêutica do instrumental. In: Escritos da Criança. Porto Alegre: Ed. Lydia Coriat, nº 3, 2a ed., 1990. ZIMERMAN, David. Vocabulário Contemporâneo de psicanálise. Porto Alegre:

Artmed, 2001. 